\title{
Justiça criminal e opinião pública na Itália entre os séculos XIX e XX ${ }^{1}$
}

\author{
Criminal Justice and Public Opinion in Italy between \\ the Nineteenth and Twentieth Centuries
}

Luigi Lacchè ${ }^{2}$

Università degli Studi di Macerata - Macerata, Italia

lacche@unimc.it

orcid.org/0000-0001-8824-8200

\begin{abstract}
Resumo: Através do exemplo italiano - mas com referências, também, à experiência de formação do chamado "sistema misto" na França e à experiência da Grã-Bretanha, tida como modelar para os reformadores continentais - o presente artigo pretende demonstrar que a "justiça criminal dos modernos" é caracterizada desde as suas origens pelo vínculo - problemático - entre justiça criminal e opinião pública. Em um primeiro momento, apesar de algumas perplexidades, a publicidade é vista como um traço indelével da justiça criminal em um regime liberal. Em um segundo momento, a publicidade passa a ser atacada - pelos juristas da escola positiva, por exemplo - como algo incompatível com a cientificidade do processo judicial, até que a própria publicidade perderia o seu significado original com o advento do fascismo.

Palavras-chave: História do processo penal; Sistema misto; Publicidade; Liberalismo; Escola positiva; Fascismo.
\end{abstract}

1 Versão com acréscimos e notas de conferência proferida no "XIII Encontros de História do Direito: Processo Penal e Modelos de Justiça entre os Séculos XIX e XX", realizado na Faculdade de Direito da Universidade Federal de Minas Gerais em Belo Horizonte-MG entre os dias 19 e 20 de abril de 2018. Tradução e revisão da língua inglesa por Marina da Costa Araújo e Ricardo Sontag. Ajustes formais por Régis João Nodari.

2 Professor catedrático de História do Direito Medieval e Moderno da Università degli Studi di Macerata (Itália). 
ABSTRACT: Through the Italian example - but also with references to the experience of the formation of the so-called "mixed system" in France and the experience of Great Britain, seen as a model for continental reformers the present article aims to demonstrate that "modern criminal justice" is characterized from its origin by the - problematic - link between criminal justice and public opinion. At first, despite some perplexities, publicity is seen as an indelible feature of criminal justice in a liberal regime. In a second moment, publicity is attacked - by scuola positiva jurists, for example - as something incompatible with the scientificity of the judicial process, until publicity itself would lose its original meaning with the advent of fascism. KEYwords: History of criminal procedure; Mixed system; Publicity; Liberalism; Scuola positiva; Fascism.

SUMÁRIO: 1. O universo da esfera pública e a justiça criminal; 2. O laboratório revolucionário e a reforma napoleônica; 3. Uma multidão de indivíduos interessados na justiça: o júri como um órgão da opinião pública; 4 . O processo positivista: contra a publicidade em nome da ciência; 5 . Considerações finais: a esfera pública judicial como pilar de um regime liberal versus justiça criminal do novo regime; Referências.

\section{O UNIVERSO DA ESFERA PÚBLICA E A JUSTIÇA CRIMINAL}

O objetivo deste artigo é abordar alguns aspectos e questões a respeito do processo penal na Itália de um ponto de vista específico: o da complexa relação entre a justiça criminal e a opinião pública. Normalmente, a opinião pública é vista como "externa”, sem relação com o direito, ou como algo que se ligou com a justiça criminal só mais recentemente. No entanto, a atual midiatização da justiça tem uma história e, desse modo, tem que ser vista em termos de uma evolução. Neste estudo, eu gostaria de salientar os vários vínculos que existem entre justiça criminal e opinião pública, e como esse tema pode ser útil para se chegar a um melhor entendimento do processo penal, inclusive no que diz respeito ao aspecto técnico.

Eu vou lidar especificamente com a história europeia, especialmente a italiana, do processo penal, mas eu acredito que a minha 
interpretação pode ser "aplicada", também, a vários outros contextos. Mas, antes de entrar na história italiana, é preciso refletir sobre alguns elementos comparativos relativos à França e à Grã-Bretanha, principalmente.

De fato, eu vou tratar de um contexto específico, mas, antes de tudo, é necessário analisar o tema como uma "estrutura profunda da modernidade". Refiro-me ao que eu definiria como a "justiça criminal dos modernos", baseada no inevitável - embora difícil - "casamento" entre justiça criminal e opinião pública. Nosso ponto de partida, "o processo penal dos modernos", implica o amplo universo do espaço público: durante o século XVIII surge a imagem da "opinião pública" como um "tribunal" diante do qual todos, até mesmo os soberanos, deveriam comparecer para serem "julgados".

Jürgen Habermas ${ }^{3}$ conceitua a esfera pública (Öffentlichkeit) como uma esfera autônoma, burguesa, que emerge da sociedade civil como uma "agência de crítica" . A esfera pública aparece como um novo espaço de "invenção política"5 na França durante o século XVIII.

Todavia, é ao longo do século XVIII que, na Inglaterra do governo representativo/parlamentar, começa-se a falar em government by opinion para assinalar a ideia de um governo da nação que deve confrontar-se com os incunábulos do pluralismo de opiniões e da sociedade. Identifica muito bem o fenômeno, observando-o depois da metade do século

3 Cf. HABERMAS, Jürgen. Strukturwandel der Öffentlichkeit. Neuwied, Berlin: Luchterhand, 1962. Trad brasileira: Mudança estrutural da esfera pública: investigações quanto a uma categoria da sociedade burguesa. Trad. Flávio R. Kothe. Rio de Janeiro-São Paulo: Brasiliense, 1990.

4 NECKER, Jacques. De l'administration des finances de la France. [S.l.]: [s.n.], 1784.

5 BAKER, Keith Michael. Politics and Public Opinion nder the Old Regime: Some Reflections. In: CENSER, Jack R.; POPKIN, Jeremy D. (orgs.): Press and Politics in Pre-Revolutionary France. Berkeley: University of California Press, 1987, p. 204-246; ID., Politique et opinion publique sous l'ancien régime, Annales Economies, sociétés, civilisations, v. 42, n. 1, p. 41-71, 1987; ID. Inventing the French Revolution: Essays on French Political Culture in the Eighteenth Century. vol. 16. Cambridge: University Press, 1990. (trad. francesa BAKER, Keith Michael. Au tribunal de l'opinion: essais sur l'imaginaire politique au 18e siècle. Paris: Payot, 1993, p. 219-265); ID. Defining the Public Sphere in Eighteenth Century France: Variations on a Theme by Habermas. In: CALHOUN, Craig (org.). Habermas and the Public Sphere. Oxford: Mit Press, 1992, p. 181-211. 
XVIII do lado francês, Jacques Necker, que vincula a responsabilidade à nascente figura retórica e contestadora do "tribunal da opinião pública". Substituída na França por um corpo representativo - como nota a sua filha, Madame de Staël ${ }^{6}$ - a opinião pública é vista como uma espécie de alta instância "judiciária" diante da qual até mesmo o rei deve prestar contas. O ministro, figura pública que governa em nome do soberano, deve ter crédito. E ter crédito significa obter confiança. Não surpreende que Necker, banqueiro/ministro, tenha se utilizado de maneira tão desenvolta de um léxico tipicamente "econômico", característico de uma Commercial Society. Escreve, ainda, a sua filha: "o crédito, então, é a verdadeira descoberta moderna que vinculou os governos aos povos. A necessidade de crédito obriga os governos a respeitar a opinião pública; e, ao mesmo tempo que o comércio civilizou as nações, o crédito que dele deriva tornou necessárias algumas formas constitucionais"7.

$\mathrm{Na}$ verdade, o problema não é somente político-constitucional no sentido mais clássico do termo, isto é, de um governo equilibrado e "misto" que limita os poderes (no plural) e as suas ações. Na dimensão constitucional - como nos mostram muito bem Blackstone ou Lolme devemos colocar em uma posição nada secundária a revolução processual ou revolução da justiça que caracteriza o século XVIII britânico, partindo de profundas raízes histórico-costumeiras dos séculos XIV e XV "reativadas” pela passagem da Revolução Gloriosa. A evolução do trial on indictment ao longo do século XVIII coloca em foco institutos e figuras que têm muita relação com a nascente public opinion: por exemplo, a ideia de um "confronto" de partes antagônicas (cada vez mais especializadas, com um papel crescente da defesa técnica, e, portanto, dos advogados), a publicidade, o papel e o desenvolvimento do jury ${ }^{8}$. Não causa estupor o fato de os iluministas continentais apresentarem um complexo discurso sobre o "problema penal" olhando, antes de tudo, para o outro lado do Canal da Mancha, por vezes com excessivo entusiasmo. Frequentemente, foi do debate em torno do direito de punir e das formas processuais que

6 DE STÄEL, A.-L. G. Considerazioni sui principali avvenimenti della Rivoluzione francese (1818). Milano: Ispi, 1943, p. 99.

7 Ibidem, p. 96.

8 Para uma clara e pontual reconstrução, remeto ao trabalho recente de DEZZA, Ettore. Breve storia del processo penale inglese. Torino: Giappichelli, 2009. 
emergiram elementos de reflexão e de crítica que, na realidade, atravessavam a sociedade como um todo. Criticava-se o sistema penal, mas, na realidade, pretendia-se criticar a estrutura da sociedade. O processo e a justiça tornam-se um termômetro.

No sistema de justiça criminal do antigo regime observável no âmbito europeu-continental, o público permanece fora do espaço processual de "tipo inquisitório", caracterizado por uma complexa gama de articulações, entrelaçamentos e variações. O caráter secreto, fechado, monista e assimétrico do rito continua sendo fundamental. Um processo que se desenvolve em segredo, pena exemplar executada em público. Este "modelo" analisado e amplamente discutido por Michel Foucault revela uma virada da penalidade na idade moderna9. Todavia, não é por acaso que a releitura crítica de Habermas e de Foucault tenham levado à reconsideração das transformações dos sistemas de justiça no final do século XVIII, adotando exatamente o paradigma da opinião pública com êxitos inovadores. Da mesma forma, não é casual que, no contexto da dicotomia secreto/público, tenha se enxertado - sobretudo na França de Voltaire e do reformismo judiciário - um gênero defensivo vinculado à natureza integralmente escrita do processo estabelecido, nas suas linhas fundamentais, pela Ordonnance criminelle de 1670, que, por sua vez, consolidou e aperfeiçoou um modelo bem definido pelas ordenações do século XVI ${ }^{10}$.

Um advogado que escreve e publica mémoires judiciaires entra no circuito dos gens de lettres, conquista fama, faz sucesso com esse tipo de texto híbrido, dotado de vocação dupla: privada e pública. Disso nasce um processo dialético: o mémoire ganha legitimidade pela opinião pública, especialmente a partir da crise constitucional do início dos anos 1770; uma crise para cuja formação ele também contribuiu. Através das causas

9 FOUCAULT, Michel. Vigiar e Punir: nascimento da prisão. Petrópolis: Vozes, 1987. Ver também as estimulantes conferências feitas por Michel Foucault em maio de 1973 na Pontifícia Universidade Católica do Rio de Janeiro e contemporâneas à preparação de Vigiar e Punir: A verdade e as formas jurídicas. Rio de Janeiro: Nau editora, 1996.

10 Sobre tudo isso, não posso fazer outra coisa senão remeter, para ulteriores referências, a LACCHÈ, Luigi. "L'opinione pubblica saggiamente rappresentata”, Giurie e corti d'assise nei processi celebri tra Otto e Novecento. In: MARCHETTI, Paolo (org.). Inchiesta penale e pre-giudizio. Una riflessione inter-disciplinare. Napoli: Esi, 2007, p. 89-147. 
célebres ${ }^{11}$, os advogados se afirmam cada vez mais como "mediadores" entre público e privado ${ }^{12}$, entre o soberano como tradicional expressão encarnada do "público" e a nação como nova instância política e social ${ }^{13}$.

Os magistrados franceses Servan, Dupaty e Boucher d'Argis falaram sobre casos de "injustiça comum" e dirigiram-se à opinião pública através de discours, lettres e mémoires justificatifs para reformar a justiça ${ }^{14}$.

11 Sobre algumas das affaires mais célebres, ver IMBERT, Jean (org.). Quelques procès criminels des XVII et XVIII siècles. Paris : Puf, 1964; BIANCO-BRUN, Yves. Le destin d'un fait divers dans l'ancien droit finissant. L'affaire des trois roués. In: AUBIN, Gérard (Org.). Liber amicorum. Études offertes à Pierre Jaubert. Bordeaux: Presses Universitaires de Bordeaux, 1992, p. 77-88. Cf. também SCHNAPPER, Bernard. La diffusion en France des nouvelles conceptions pénales dans la dernière décennie de l'Ancien Régime. In: BERLINGUER, Luigi; COLAO, Floriana (orgs.). Illuminismo e dottrine penali. Milano : Giuffrè, 1990, p. 409-433.

12 Sobre o ponto, ver, pelo menos, os trabalhos de Sarah MAZA: Le tribunal de la nation: les mémoires judiciaires et l'opinion publique à la fin de l'ancien régime. Annales Economies, sociétés, civilisations, v. 1, p. 73-79, 1987; ID. Private Lives and Public Affairs. The Causes Célèbres of Prerevolutionary France. Berkeley: University of California Press, 1993.

13 Cf., por exemplo, as "causes célebres" publicadas pelo advogado François Gayot de Pitaval em 18 volumes (1734-1741). Sobre a relação entre criminalidade, persecução penal e formas literárias, cf. em particular CARO BAROJA, Julio. Ensayo sobre la literatura de cordel. Madrid: Istmo, 1990 (1969); LÜSEBRINK, Hans-Jürgen. Kriminalität und Literatur im Frankreich des 18. Jahrhunderts. Literarische Formen, soziale Funktionen und Wissenskonstituenten von Kriminalitätsdarstellung im Zeitalter der Aufklärung. München-Wien: Oldenbourg Verlag, 1983; LEVER, Maurice. Canards sanglants. Naissance du fait divers. Paris: Fayard, 1993; DE ROMANIS, Roberto; LORETELLI, Rosamaria (orgs.). Il delitto narrato al popolo. Immagini di giustizia e stereotipi di criminalità in età moderna. Palermo: Sellerio, 1999; BIET, Christian. L'opinion publique, le théâtre, le pouvoir, le droit et le brigand. L'affaire Cartouche (1721). In: GAUVARD, Claude (org.). La justice en l'an mil. Paris: Association française pour l'histoire de la justice, 2003, p. 171-185; MAZZACANE, Alado. Letteratura, processo e opinione pubblica. Le raccolte di cause celebri tra bel mondo, avvocati e rivoluzione. Rechtsgeschichte, v. 3, 2003, p. 70-97.

Sobre esses personagens e suas intervenções v. MARTUCCI, Roberto. La Costituente ed il problema penale in Francia (1789-1791). I. Alle origini del processo accusatorio: i decreti Beaumetz. Milano: Giuffrè, 1984, p. 13 et seq.; ID., Opinion frondeuse, opinion éclairée, opinion publique nella Francia di Antico regime. In: LACCHÈ, Luigi (org.). Opinione pubblica. Storia, politica, costituzione dal XVII al XX secolo. Número monográfico do Giornale di storia costituzionale, v. 6, semestre II, 2003, p. 119 et seq. 
Os philosophes e os juristas reformadores contribuíram para redefinir os termos fundamentais do direito de punir, abrindo a "revolução epistemológica" do processo que, no giro de poucas gerações, transformou e ultrapassou o léxico da justiça penal do antigo regime, acuando o sistema das provas legais e da tortura judiciária, o arbitrium judicis e a penalidade exemplar com crescentes avaliações negativas.

Para usar uma imagem capaz de resumir tudo isso, apesar de simplificadora, podemos dizer que, na Inglaterra do século XVIII, o "matrimônio" entre processo e opinião pública já tinha fortes enraizamentos sociais, institucionais e técnicos. Como não lembrar que, já nas primeiras décadas do século, os irmãos Fielding (John era magistrado) contribuíam, com as histórias de processos e com o ingresso de jornalistas na sala de audiência, para dissipar a opacidade da justiça? Na França do século XVIII (assim como em boa parte da Europa), a opinião pública é vista como um tribunal em potencial: começa a criar raízes no plano social, mas permanece sendo uma referência simbólica no âmbito da justiça praticada. Passando pelo reformismo iluminista e pelo cadinho da Révolution é que tal matrimônio começa a tomar forma, generalizando-se ao longo do século XIX. Então, a opinião pública (acompanhada do olhar "popular" e da imprensa) entra com força nos tribunais e toma corpo uma renovada antropologia da justiça.

Uma nova constelação de conceitos vincula-se ao surgimento sociológico da opinião pública: publicidade, conhecimento, responsabilidade. Aqui eu só vou poder identificar os aspectos mais diretamente ligados ao nosso tema. O paradigma de Habermas não leva em consideração a justiça como um espaço de publicidade (racional, universal, objetivo, etc.), todavia, eu acredito que ela é um "espaço" relevante em que podemos discernir tensões e contradições.

\section{O LABORATÓRIO REVOLUCIONÁRIO E A REFORMA NAPOLEÔNICA}

Olhemos por um instante para o outro lado do Canal da Mancha, isto é, para o trial on indictment e para o trial by jury ingleses, em particular para o desenvolvimento deles no século XVIII, que eram pontos de referência para os reformadores europeus. 
Tratava-se de uma justiça que se desenvolveu a partir de uma evolução secular, regida pela publicidade, pela oralidade e pelo modelo adversarial (defence counsel) baseado na investigação, no interrogatório cruzado e em algumas regras probatórias.

O "processo penal britânico" poderia realmente ser transplantado para a Europa continental?

Analisemos o caso francês.

A reforma Beaumetz ${ }^{15}$ (8-9 de outubro de 1789, Décret sur la réformation de quelques points de la jurisprudence criminelle) é a primei$\mathrm{ra}^{16}$ tentativa revolucionária de reformar o processo até então baseado na Ordonnance criminelle de 1670. A fase de investigação do julgamento deveria ser realizada na presença de dois 'cidadãos' (adjoints), com a possibilidade de consultar com o advogado e conhecer os documentos. É uma investigação pública e adversarial. Entre 1790 e 1791, várias leis reorganizam o processo criminal, atribuindo um poder considerável à justiça de paz (juge de paix) e instituindo o júri popular (jury populaire) como um protagonista essencial no processo ${ }^{17}$.

A Revolução Francesa levantou alguns pilares da "nova" justiça, mas não alcançou uma reforma completa, orgânica e duradoura do processo

15 Cf. MARTUCCI. La Costituente (op. cit.).

16 Precedida pela ineficaz reforma Lamoignon de maio de 1788 e pelo projeto Bergasse (apresentado em 17 de agosto de 1789 em nome do segundo Comité de Constitution).

17 "O juiz de paz, eleito pelo povo, tornou-se, efetivamente, a chave do système d'instruction [...]". Imitando o sistema inglês, os jurados decidem sobre a acusação (jury d'accusation) e, depois, julgam os crimes (jury de jugement). O júri, em matéria penal, era composto por cidadãos que não eram advogados nem magistrados profissionais. "A dénonciation civique tornou-se, assim, o pilar do procedimento, associada à ideia de que formava parte integrante da responsabilidade cidadã e cívica. O procedimento criminal tornou-se público e uma representação da apropriação pela soberania popular de um mecanismo controlado pelo Estado. Esse mecanismo não estava mais nas mãos de um poder estatal autônomo e o accusateur public e o commissaire du roi, precursores da procuradoria moderna da França, não podiam intervir sem a iniciativa do juge de paix. Um processo judicial do estado como tal não era mais possível" (ZACHARIE, Clémence. The Code d'instruction criminelle, 1808. In: The History Website of the Fondation Napoleon, 2008. Disponível em https:// www.napoleon.org/en/history-of-the-two-empires/articles/the-code-dinstruction-criminelle-1808/. Acesso em 30 nov. 2020). 
penal. Durante esse período, acabou sendo impossível estabilizar o sistema de justiça. Esse objetivo foi alcançado durante o período napoleônico. $\mathrm{O}$ clima estava mudando. Os debates da época revelam a animosidade dos magistrados em relação aos membros do júri, que eles criticavam como generosos demais, tolerantes e tímidos, qualidades que prejudicariam a eficácia do júri na busca pela justiça. Napoleão precisava de um sistema de repressão mais autoritário e eficaz.

Um número significativo de juristas (incluindo figuras importantes como Siméon e Portalis) pensavam que era preciso restabelecer o sistema delineado na Ordonnance de 1670, acrescentando o princípio dos defence counsels e a publicidade dos procedimentos.

O Code d'instruction criminelle (1808) foi um compromisso jurídico e político, uma combinação de princípios jurídicos do Ancién Régime com aqueles inspirados pelo período revolucionário. Foi, portanto, um trabalho de notável estabilidade e constituiu a base do processo penal moderno em vários aspectos.

O jury d'accusation foi abolido definitivamente e suas responsabilidades e deveres foram transferidos para uma câmara especial da cour d'appel, chamada chambre de mise en accusation. Os magistrados seriam novamente os encarregados da persecução e, assim, envolveram-se no fortalecimento do princípio da ação do Estado em matéria penal.

O júri popular (doze membros selecionados) permaneceu apenas para o julgamento dos crimes, dirigido pelo presidente da Cour d'Assises. Os processos eram conduzidos oralmente, publicamente e abertamente, e o acusado era assistido por um advogado. O júri daria seu veredicto e a sentença seria fixada por magistrados profissionais.

O Code d'instruction criminelle (1808) tornou-se o modelo mais importante do "sistema misto", assim chamado devido à justaposição de duas fases:

1) Fase de investigação (instruction) dominada pela permanência da lógica "inquisitorial" (secreta, essencialmente escrita, com um papel muito limitado para a defesa) para proteger os interesses do poder público;

2) Fase de julgamento (débat) marcada por alguns elementos do sistema "adversarial" (publicidade, oralidade, interrogatório, júri) para garantir o indivíduo e seus direitos. 
Esse "modelo" (europeu) ${ }^{18}$ espelha muito bem as tensões e conflitos do século XIX entre ordem e liberdade, autoridade e direitos individuais. A "justiça dos modernos" repousa sobre essas características e o "sistema misto" não é apenas um "quadro técnico" para um processo.

Os romancistas perceberam de imediato o potencial literário e dramatúrgico dessa "estrutura justaposta": primeiro, a investigação secreta e, depois, a publicidade e a luta para descobrir a "verdade". Honoré de Balzac é, provavelmente, o romancista com a mais profunda compreensão do potencial desse "mecanismo". A fase secreta é uma fonte de conjecturas, invenções, curiosidades. Mas, "na frente de um tribunal criminal tudo depende do julgamento e o debate se concentrará em pequenas coisas que você verá se tornarem imensas" (Une ténébreuse affaire, 1841). Stendhal escreveu $O$ Vermelho e o Negro inspirado na Gazette des Tribunaux (1825): “[s]eria inútil apontar para o público essa multidão de pessoas que passam diariamente nos bancos do Júri e da Polícia Correcional?”.

\section{UMA MULTIDÃO DE INDIVÍDUOS INTERESSADOS NA JUSTIÇA: O JÚRI COMO UM ÓRGÃO DA OPINIÃO PÚBLICA}

O "sistema misto" é, na Europa, o coração da esfera pública judicial. E a esfera pública judicial, por sua vez, é um espaço constitucional.

Na Itália, esse "espaço" começou a tomar forma a partir de 1848. Em março de 1848, o Reino "constitucionalizado" da Sardenha estabeleceu, pela primeira vez, o júri para julgar crimes relacionados à imprensa. O júri ingressou nas salas de audiência italianas exatamente com o Édito sobre a imprensa de 26 de março de 1845, que se tornaria um dos pilares do ordenamento liberal italiano. O Édito abolia a censura prévia e reconhecia aos "crimes de imprensa", em geral, um regime jurídico favorável, seguindo - na linha do modelo doutrinário francês - a lógica da especialidade e do caráter intrinsecamente político

18 ALESSI, Giorgia. Le contraddizioni del processo misto. In: MARMO, Marcella; MUSELLA, Luigi (org.). La costruzione della verità giudiziaria. Napoli: Cliopress, 2003, p. 7-52. 
do crime de opinião. Esse vínculo explica-se pelo fato de o júri ser um órgão de representação da opinião pública no processo. E quem melhor do que a opinião pública - selecionada de acordo com critérios censitários e de capacidade que, progressivamente, forjaram a cidadania política - poderia julgar os crimes de imprensa que, frequentemente, são crimes de opinião?

O júri, dizia a lei, é "o elemento essencial de uma opinião pública sabiamente representada”. Essa "força”, a opinião pública, é o "juiz natural” das opiniões emitidas através da imprensa. O júri, então, era tido como um dos quatro pilares de um regime constitucional, juntamente com o parlamento, uma imprensa livre e a guarda nacional ${ }^{19}$.

Tratava-se de uma espécie de mito do júri, pois ele era visto como uma instituição constitucional e "democrática”, julgando a própria opinião pública, controlando os magistrados profissionais e o sistema judicial, introduzindo o "senso comum" dentro do aparato judicial.

Em 1859, o júri é inserido nas corti d'assisi com competências mais amplas, incluindo os crimes de imprensa, crimes políticos, mas também crimes comuns mais sérios. Em 1865, é promulgado o primeiro código penal italiano com base no modelo do "sistema misto" (inspirado, por sua vez, no código do Reino da Sardenha e no modelo francês de 1808). Em 1874, uma lei orgânica consolida o júri no sistema criminal italiano. Ou seja, a partir da década de 1870 acontece uma nacionalização da justiça (tida como uma parte relevante da "construção da nação") e uma incipiente midiatização da justiça (publicidade indireta). Nesse momento, encontramos os primeiros processos famosos acompanhados pela imprensa nacional e pela opinião pública, em que as corti d'assisi são o principal "teatro" desses fenômenos.

A reforma de 1874 e o vasto debate que a acompanha, nos parlamentos e no âmbito doutrinário, respondem à exigência de neutralizar alguns dos problemas já relevados pelos comentadores: as absolvições "escandalosas", na linha do que tinha acontecido na França desde a Restauração, a apatia dos jurados, as tipologias de composição do órgão e o abuso do sistema de dispensas. Em 1872, Enrico Pessina sintetizou

19 CARRARA, Francesco. I giurati e la libertà. Prolusione al corso accademico di diritto penale dell'anno 1874-75. Lucca: Giusti, 1874, p. 11. 
bem o problema da natureza dupla do júri: "o júri como instituição política atrai os homens; o júri como instituição judiciária atrai contra si desconfiança e medo..." ${ }^{20}$.

A referida lei de 1874 consolida o papel do júri criminal, mas, ao mesmo tempo, traz à tona o problema da publicidade direta e indireta das audiências judiciais, bem como a crescente pressão da opinião pública na esfera pública judicial. $\mathrm{O}$ art. 72 do Estatuto Albertino (a Constituição do Reino da Itália) prescreve a aplicação - “conforme às leis” - do princípio da publicidade, seja para as audiências dos tribunais em matéria cível, quanto para os debates em matéria criminal. O art. 268 do código de processo penal de 1865 estabelece o princípio geral segundo o qual as audiências diante das cortes, dos tribunais e dos pretores são públicas sob pena de nulidade, salvo as exceções expressamente previstas. A lei de 1874 introduz algumas limitações à publicidade indireta. De fato, o art. 49 da Lei de 1874 proibia a

publicação, por meio da imprensa, dos documentos da fase escrita, das sentenças e das acusações e dos resumos dos procedimentos dos processos penais, antes da sentença final ser pronunciada. A publicação do nome dos jurados e dos juízes e dos votos individuais também é proibida.

O objetivo era "subtrair o júri das influências nefastas" da imprensa, feitas através de seus relatos parciais e apaixonados. Sendo o "isolamento físico" (como na tradição anglo-saxônica) inviável, a justiça precisa, pelo menos, do "isolamento moral” dos jurados e juízes.

Todavia, esse artigo da lei de 1874 foi criticado pelos juristas liberais e pela opinião pública. O jurista Luigi Lucchini, por exemplo, asseverava que a publicidade das audiências é uma das realizações mais importantes dos regimes liberais e constitucionais. $\mathrm{O}$ isolamento da justiça poderia ser muito perigoso.

Em 1876, o ministro da justiça Pasquale Stanislao Mancini propõe uma mudança:

20 PESSINA, Enrico. Della istituzione dei giurati nei giudizi penali (1872). In: Opuscoli di diritto penale. Napoli: Marghieri, 1874, vol. I, p. 298. 
Não se pode negar que os relatórios da imprensa ampliam essa publicidade, eles consolidam essa garantia, porque permitem que, além daqueles poucos que podem entrar no tribunal de justiça, toda a nação, e talvez todo o mundo civilizado, possam testemunhar o drama judicial (...). Essa não é apenas uma vã curiosidade, mas a aplicação de um grande princípio: a proteção da justiça, a custódia da independência daqueles que são chamados a administrá-la.

A lei n. 3814 de 6 de maio de 1877, então, restabeleceria a publicidade por meio de imprensa, relatórios, procedimentos e resumos do processo.

Nos anos seguintes, os ministros da justiça, em diferentes ocasiões, enviaram instruções aos magistrados, estimulando-os a manter a tranquilidade, a solenidade e a decência nos tribunais ${ }^{21}$. "Eu ouvi" - escreveu um ministro em 1879 - "sobre debatedores nos tribunais e presidentes distribuindo ingressos de primeira e segunda classe. Essas exibições teatrais são repugnantes ao decoro dos magistrados de uma nação civilizada”. Outro ministro da justiça, em 1891, criticou a prática de distribuição de assentos privilegiados, especialmente o acesso de pessoas que, seja por causa de seu sexo ou por sua posição social, deveriam se abster e não ceder ao desejo mórbido de participar de debates criminais.

O teatro da justiça: eis uma metáfora recorrente. As salas de audiências como "teatros", representando dramas reais. A justiça como uma performance envolvendo muitos personagens (réus, vítimas, juízes, promotores, advogados, especialistas, jornalistas, o público). O jurista e sociólogo Scipio Sighele, em um livro chamado Letteratura tragica, escrevia em 1906 que

é verdade (...) que a maioria do público é atraída pelas histórias dos crimes, e eles procuram os detalhes, comentam sobre eles e os estudam, e se tornam, dia após dia, mais interessados por eles. Se há um tipo de literatura que está hoje na moda é, sem dúvida, a literatura dos julgamentos. Esses dramas que realmente

21 Sobre as circulares, ver PISANI, Mario. Quattro circolari sulla pubblicità del dibattimento. Quaderni fiorentini per la storia del pensiero giuridico moderno, v. 2, p. 703-716, 1973; LACCHÈ, Luigi. Una letteratura alla moda. Opinione pubblica, «processi infiniti» e pubblicità in Italia tra Otto e Novecento. In: MILETTI, Marco N. (org.). Riti, tecniche, interessi. Il processo penale tra Otto e Novecento. Milano: Giuffrè, 2006, p. 459-513. 
foram vividos e que têm seu epílogo na corte d'assisi são muito mais interessantes do que os dramas imaginários representados nos palcos dos teatros. E nós os acompanhamos pela imprensa seja na crônica precipitada do jornal diário ou no livro que é, ou pretende ser, imparcial e científico - com uma intensidade que é impulsionada pelo ritmo de nossa ansiedade febril ${ }^{22}$.

A publicidade, assim, tinha duas faces: por um lado, ela era o pilar político e constitucional da "justiça dos modernos", conectando a justiça à nação e à constituição, “democratizando" as cortes de justiça; por outro, a publicidade era um princípio que trazia em si o risco de degradar a justiça em sua solenidade, decoro e estabilidade.

A "teatralização" da justiça dependia, essencialmente, de quatro aspectos: 1) o "sistema misto" (do código de 1865) que negava as garantias básicas durante a fase secreta de investigação e acusação. Assim, o debate público faz com que as contradições e conflitos aumentem durante as longas audiências, especialmente nas corti d'assisi ${ }^{23} ; 2$ ) a consequência é que os julgamentos eram intermináveis; 3) o lugar do júri; 4) o papel da imprensa e dos jornalistas (o crescente "quarto poder").

O já citado Scipio Sighele enfatizava um "paradoxo": enquanto toda atividade humana tendia a se especializar, no que diz respeito à justiça, ao contrário, havia uma tendência à generalização. Então, todo mundo tinha uma opinião sobre justiça... Segundo o sociólogo Gabriel Tarde ${ }^{24}$, a sua época estaria dominada pelo público considerado como uma entidade civil e moderna. Já Sighele pensava que público e multidão coexistem, e o público poderia facilmente se transformar em uma multidão que, segundo ele, seria um fenômeno bárbaro e atávico.

22 SIGHELE, Scipio. Letteratura tragica. Milano: Treves, 1906, p. 246. Desenvolvi essa análise no artigo Una letteratura alla moda (op. cit.).

23 Cf. LACCHÈ, Luigi. Un luogo «costituzionale» dell'identità giudiziaria nazionale: La Corte d'assise e l'opinione pubblica (1859 1913). In: COLAO, Floriana; LACCHÈ, Luigi; STORTI, Claudia (Orgs.). Processo penale e opinione pubblica in Italia tra Otto e Novecento. Bologna: Il Mulino, 2008, p. 77-120.

24 TARDE, Gabriel. Le Public et la Foule. Revue de Paris, n. 15 juillet e $1^{\mathrm{o}}$ août 1898. Cf. REYNIÉ, Dominique. Gabriel Tarde, théoricien de l'opinion. Paris: Puf, 1989. 


\section{O PROCESSO POSITIVISTA: CONTRA A PUBLICIDADE EM NOME DA CIÊNCIA}

A Escola Positiva estava muito interessada na multidão e nos "fenômenos coletivos". "A dimensão coletiva" - escreveu Scipio Sighele em uma carta a Gabriel Tarde - "seja ela chamada de júri ou comissão, assembleia ou multidão, dá origem a um produto moral e intelectual pior do que faria cada um dos homens que a compõem. Unir-se, no mundo humano, portanto, quer dizer piorar-se" 25 . Para Cesare Lombroso e os positivistas, a multidão e outras entidades "coletivas" expressam algo negativo.

Sighele e os principais expoentes da Escola Positiva pretendiam afirmar a primazia italiana na identificação e elaboração científica dos temas da multidão delinquente e da psicologia coletiva, seja invocando as ideias "embrionárias" de Lombroso ${ }^{26}$ ou as de $\mathrm{Ferri}^{27}$. O próprio Ferri dizia: "eu apliquei - antes de Sighele publicar seu excelente volume sobre a multidão delinquente - aquela teoria psicossociológica, sobre o crime coletivo, que agora tornou-se dominante" ${ }^{28}$. Além disso, Ferri insistia, sobretudo, que Sighele - "tão feliz amante desse novo território" - publicou primeiro, ainda muito jovem, um trabalho monográfico em $1891^{29}$, traduzido com sucesso para o francês já em 1892, enquanto eram posteriores as principais obras de Gustave Le Bon $^{30}$ e de Tarde.

25 SIGHELE, Scipio. Lettera di Scipio Sighele a Gabriel Tarde. Critica sociale, $1^{\circ}$ novembre, 1894, depois em apêndice em SIGHELE, Scipio. L'intelligenza della folla. Torino: Bocca, 1922, p. 137-145, citado por MANGONI, Luisa. Una crisi fine secolo. La cultura italiana e la Francia fra Otto e Novecento. Torino: Einaudi, 1985, p. 138 [grifos nossos].

26 Sobretudo na questão do crime político em LOMBROSO, Cesare. Il governo e la piazza. In: Il momento attuale. Milano, Casa editrice moderna, 1903, p. 65.

27 FERRI, Enrico. I nuovi orizzonti del diritto e della procedura penale. Bologna: Zanichelli, 1881, p. 57-58.

28 FERRI, Enrico. Ricordi e consigli di psicologia oratoria. La Scuola positiva, vol. 8, 1898, p.518.

29 SIGHELE, Scipio; La folla delinquente. Torino: Bocca, 1891.

30 LE BON, Gustave. Psychologie des foules. Paris: Félix Alcan, 1895. 
Em La Scuola Positiva e em outras revistas, a polêmica desencadeada, acima de tudo, pelo suposto plágio de Le Bon, teve grande destaque ${ }^{31}$. O próprio Sighele dedicou uma parte do volume L'intelligenzza della folla ${ }^{32}$ para o problema da genealogia e dos conteúdos das categorias ${ }^{33}$.

Voltando ao nosso ponto, o problema era que a opinião pública se transformaria em uma multidão diante dos dramas "performados" nos tribunais. Para a perspectiva positivista, o júri é manifestamente inorgânico ${ }^{34}$, primitivo, porque contradiz o princípio da divisão do trabalho e introduz o senso comum onde é preciso de ciência e de um conhecimento cada vez mais especializado do homem delinquente ${ }^{35}$;

31 Ver, em particular a coleção de cartas e posições tomadas por Sighele, Ferri, Tarde e Le Bon em Polemica sulla Psychologie des foules. La Scuola Positiva. v. 1,1895 , p. 367-375.

32 SIGHELE, Scipio. L'intelligenza della folla. Torino: Bocca, 1931.

33 Sobre o fenômeno em questão e sobre o complexo sistema de ideias, percepções e obras que se desenvolveram em paralelo entre a França e a Itália, é fundamental MANGONI. Una crisi fine secolo (op cit.). Mais em geral, ver MUCCHI FAINA, Angelica. L'abbraccio della folla. Cento anni di psicologia collettiva. Bologna: Il Mulino, 1983; PALANO, Damiano. Il potere della moltitudine: l'invenzione dell'inconscio collettivo nella teoria politica e nelle scienze sociali italiane tra Otto e Novecento. Milano: Vita \& Pensiero, 2002. O caso francês já havia sido bem analisado por Susanna Barrows, Distorting Mirrors. Visions of the Crowd in Late Nineteenth Century France. New Haven: Yale University, 1981. Entre os escritos de Sighele do final do século, vale a pena mencionar, por exemplo, La teorica positiva della complicità. Torino: Bocca, 1894 e La Delinquenza settaria. Milano: Treves, 1897. Sighele, então, sublinha a "recepção" jurisprudencial de suas ideias em I delitti della folla studiati secondo la psicologia, il diritto e la giurisprudenza e coll'aggiunta di tutte le sentenze pronunciate dai Tribunali e dalle Corti d'appello in tema di delitto collettivo. Torino: Bocca, 1902.

DE LUCA, Franceso. L'evoluzione e la giuria. Girgenti: Formica e Gaglio, 1893.

Sobre o júri como um "verdadeiro regresso", ver FERRI, Enrico. I nuovi orizzonti del diritto e della procedura penale. Prolusione al corso di diritto e procedura penale detta nell'Università di Bologna il 6 dicembre 1880. Bologna: Zanichelli, 1881, p. 132. "Per la scienza non esiste il fatto, ma soltanto la legge: per il senso comune ed il buon senso invece la vivacità del fatto presente costituisce l'unica preoccupazione, senza la ricerca dei legami nascosti onde i fatti diversi si contessono in una legge generale. Di qui la tendenza inevitabile nel giurì a lasciarsi sopraffare dagli avvenimenti isolati, guidato dal sentimento di malintesa compassione..., o dal sentimento di vendetta... D'onde una giustizia passionata e miope, che ben poco prestigio può avere sul popolo" (FERRI, Enrico. Sociologia criminale, $3^{\mathrm{a}}$ ed. Torino: Bocca, 1892, p. 666). 
ele se compõe, enfim, não dos melhores, que se desobrigam graças a dispensas e recusações, mas de uma "reunião de merceeiros, barbeiros e locatários" ${ }^{36}$, prontos a fraquejar diante dos crimes mais graves e ameaçadores, inclusive através de uma equívoca interpretação da "força irresistível" ${ }^{37}$ e das escusas e dirimentes, e excessivamente severos como mostrarão os seguidores do socialismo jurídico - em relação aos crimes contra a propriedade ${ }^{38}$.

Por outro lado, para eles, o "processo" não é apenas um caminho para a busca da verdade, mas deve ser também um experimento antropológico com o criminoso em carne e osso, e não com uma entidade "abstrata".

Em 1893, o juiz Camillo Cavagnari, em La Scuola Positiva, reivindicava que a publicidade das audiências criminais fosse abolida ${ }^{39}$. O

36 GAROFALO, Raffaele. Criminologia. Studio sul delitto e sulla teoria della repressione. Torino: Bocca, 1891, p. 425. A posição de Garofalo é bem representativa de um amplo front crítico em relação à instituição do júri na ótica da defesa social: "Si può affermare che in Italia l'opinione pubblica sia decisamente avversa a tale istituzione, e che l'avversione cresca quanto più la macchina si vede funzionare dappresso. Se gli uomini politici e molti giornali dànno ad intendere di pensarla diversamente, ciò dipende dal pregiudizio, a cui ho accennato poc'anzi, che confonde tale istituzione con le prerogative di un libero paese".

37 Cf. GIANI, R. I giurati e la forza irresistibile. La Scuola Positiva, v. 1, p. 324-325, 1891; FERRI, Enrico. L'art. 46 c.p. nelle Corti d'Assise. La Scuola Positiva, v. 3, p. 10-19, 1893; FROLA, P.E. L'ubriachezza alle Corti d'Assise. La Scuola Positiva, v. 3, p. 105-110, 1893.

38 Cf., por exemplo, IMPALLOMENI, Giovanni Battista. Della giuria. Discorso inaugurale letto il 4 novembre 1894 nella R. Università di Palermo. Palermo: Lo Statuto, 1895; POZZOLINI, Alfredo. L'idea sociale nella procedura penale. Appunti critici. Archivio giuridico, v. 60, p. 305-319, 1898; v. 61, p. 30-62, p. 279-303, 1898; FLORIAN, Eugenio. Le due giustizie. Rivista di diritto e procedura penale, p. 143-149, 1910. Para as diversas posições doutrinárias sobre os defeitos do júri e sobre os remédios propostos, ver STORTI, Claudia. Giuria penale ed errore giudiziario: questioni e proposte di riforma alle soglie della promulgazione del codice di procedura penale italiano del 1913. In: GOURON, André; MAYALI, Laurent; PADOA SCHIOPPA, Antonio; SIMON, Dieter (orgs.). Error iudicis. Juristische Wahrheit und justizieller Irrtum. Frankfurt am Main: V. Klostermann, 1998, p. 261 et seq.

39 "Non si dica" - acrescenta Lanza - "che le mie sono idee antidiluviane, $e$ che la pubblicità dei giudizî è una delle conquiste della civiltà moderna, conquista, che non giova di abbandonare per vani ed esagerati timori: non si dica questo. Non siamo nemici della pubblicità, ma dell'abuso della medesima. Una 
sucesso de debates públicos sobre crimes e o grande interesse da opinião pública em reportagens jornalísticas e na chamada "literatura de julgamentos famosos" teriam consequências danosas. Essas audiências públicas seriam "criminógenas" e "promoveriam" uma espécie de "contágio do mal”. Mas, segundo Cavagnari, existe, antes e acima de tudo, uma razão técnica para proibir a publicidade e a consequente midiatização: os positivistas defendem a esterilização médica do processo, isto é, o "processo positivista" é visto como um experimento científico e, portanto, apenas os especialistas poderiam participar ${ }^{40}$.

A publicação de relatórios judiciários é danosa em qualquer sentido e, principalmente, para o bom andamento do processo. "Todos os jornais estão sempre cheios e transbordando de relatórios judiciários dos delitos mais atrozes, impressionantes e escandalosos, que são aqueles que interessam mais; e o gosto do público depravou-se, fascinado por esse triste gênero de literatura..." ${ }^{41}$ que se difunde na sociedade como um perigoso contágio ${ }^{42}$.

A publicidade nasceu como uma garantia política e constitucional, mas seria incompatível com o isolamento necessário nessas concepções de processo. Para Eugenio Florian, a publicidade dos debates e os relatos da imprensa continuavam elementos necessários da "justiça democrática”, já que "a opinião pública percebe os defeitos e lacunas da legislação penal, que é aquela que tem mais contato com os sentimentos e necessidades

pubblicità moderata e ben intesa è un giusto controllo, è una guarentigia della giustizia, è una conseguenza della libertà e della coscienza dei popoli, e noi la vogliamo; ma una pubblicità esagerata, che si converte in teatralità, è un tossico pericoloso, da cui giova preservarsi" (LANZA, Pietro. Il processo infinito. Osservazioni in occasione del processo Cifariello. Rivista penale, v. 18, 1908, p. 348).

40 CAVAGNARI, Camillo. La pubblicità dei dibattimenti e l'educazione del carattere. La Scuola positiva, v. 3, p. 216-224, 1893. Cavagnari inspira-se largamente em SERGI, Giuseppe. L'educazione del carattere. 2 ed. Milano: Dumolard, 1893, p. 250 et seq. Ver também CAVAGNARI, Camillo. Ancora della pubblicità dei dibattimenti e l'educazione del carattere. La Scuola positiva, v. 3, p. 508, 1893.

${ }^{41}$ LANZA, Pietro. Il processo infinito (op cit.), p. 348.

${ }^{42}$ Sobre o tema da sugestão e da imitação induzidas pela imprensa, ver SIGHELE, Scipio. Letteratura tragica (op. cit.), p. 269 et seq. 
do povo (...), o que resultará vantajoso especialmente nas formas de Estado largamente democráticas, para as quais a sociedade moderna está se encaminhando inevitavelmente" ${ }^{43}$.

Entre o final do século XIX e a primeira guerra mundial, o curto-circuito que se determinou na relação entre publicidade dos debates, papel da imprensa, processos célebres, júris e "representação" da opinião pública alcança um primeiro ápice. Todavia, não obstante existam boas razões para vetar a publicação dos relatos processuais, um autor como Pietro Lanza diz que não se ilude: o "jornalismo está muito interessado em manter aquelas seções de jornais que, infelizmente, são mais atraentes para o público e, portanto, garantem uma fonte perene de renda. $\mathrm{O}$ jornalismo de toda parte concordaria em se opor a um passo tão novo. E quem teria forças para resistir ao terrível impacto do quarto poder? Quem ousaria desafiá-lo e combatê-lo?" ${ }^{44}$

O novo Código de Processo Penal de 1913 tentou regular melhor a publicidade das audiências ${ }^{45}$. Os presidentes dos tribunais não podiam mais reservar lugares especiais ao público - a menos que fossem jornalistas - e poderiam fechar os tribunais por razões de "interesse público", bem como por considerações morais e de ordem pública ${ }^{46}$.

43 FLORIAN, Eugenio. Pel diritto di conoscere i fatti criminosi. La Scuola positiva, v. 3, 1893, p. 322.

LANZA, Pietro. Il processo infinito (op cit.), p. 350.

45

MILETTI, Marco N. Un processo per la Terza Italia. Il codice di procedura penale del 1913. vol. I, L'attesa, Milano: Giuffrè, 2003.

O art. 373 do código de processo penal de 1913 - que toma o lugar do art. 268 do código de processo penal de 1865 - estende ao "interesse público" (além da moral e da ordem) a faculdade de fazer com que o processo se desenrole a portas fechadas. Era vetada, ainda, a publicidade das audiências quando o imputado presente não tivesse cumprido dezoito anos. O ingresso na sala era negado, também, a quem fosse conhecido como admoestado, vigiado especial, ocioso ou vagabundo e, da mesma forma, aos menores de dezoito anos. $\mathrm{O}$ art. 383 colocava algumas regras de comportamento a serem respeitadas pelos participantes da audiência: estar com a cabeça descoberta em silêncio, sem manifestar concordância ou desaprovação. Ao longo da discussão parlamentar, alguns propuseram vetar ao "gentil sesso" a participação nos debates. 


\section{Para concluir: a esfera pública judicial como pilar de UM REGIME LIBERAL VERSUS JUSTIÇA CRIMINAL DO NOVO REGIME}

A esfera pública judicial, baseada na liberdade de imprensa, na publicidade das audiências e no papel do júri penal, foi, como vimos, um dos pilares do regime constitucional. Ela poderia ser "limitada", mas não eliminada. Ela era uma das várias faces da vital e inafastável dialética entre a ordem e a liberdade que dava forma às sociedades modernas liberais e democráticas.

Na Itália, a "alternativa" chegaria com o advento do fascismo. Em 1928, o ministro da justiça Alfredo Rocco emanava uma circular relativa à disciplina das audiências para lembrar que "as salas de justiça devem adquirir cada vez mais o caráter de templo austero, e o exercício da solene função deve se desenvolver com o absoluto respeito que lhe é devido" ${ }^{47}$. Além disso, a demanda por aplicação rigorosa das disposições do código de $1913^{48}$ e, dois anos depois, do código de 1930, permitia que o presidente de um tribunal proibisse a publicidade e, também, que evitasse a "curiosidade negativa" do público em relação aos julgamentos (art. 423, c.2, C.P.P. 1930).

É evidente que a publicidade, a essas alturas, já havia perdido seu significado original. O fascismo tinha abolido a liberdade de imprensa e estava prestes a se livrar dos júris. A única esfera pública judicial compatível com o novo regime autoritário seria aquela funcional à politização da justiça e a uma transformação completa do Estado.

\section{REFERÊNCIAS}

ALESSI, Giorgia. Le contraddizioni del processo misto. In: MARMO, Marcella; MUSELLA, Luigi (orgs.). La costruzione della verità giudiziaria. Napoli: Cliopress, 2003. p. 7-52.

47 Cit. por PISANI, Mario. Quattro circolari (op. cit.), p. 714. No que diz respeito aos relatórios escandalosos e as relativas fotografias de delinquentes, suicidas, etc., eles foram vetados a partir de 1925.

48 Ferri observa como as disposições do código de 1913, ainda que dignas de elogio, permaneceram quase sempre sem aplicação (FERRI, Enrico. Sociologia criminale. 5 ed. Torino: Utet, 1929, vol. I, p. 536). 
BAKER, Keith M. Politique et opinion publique sous l'Ancien Régime. Annales. Economies, sociétés, civilisations, v. 42, n. 1, p. 41-71. Cambridge: University Press, 1987. https://doi.org/10.3406/ahess.1987.283368

BAKER, Keith M. Au tribunal de l'opinion: essais sur l'imaginaire politique au 18e siècle. Paris: Payot, 1993.

BAKER, Keith M. Inventing the French Revolution: Essays on French political culture in the eighteenth century. vol. 16. Cambridge: University Press, 1990. https:// doi.org/10.1017/cbo9780511625527

BAKER, Keith M. Politics and Public Opinion Under the Old Regime: Some Reflections. p. 204-246. In: CENSER, Jack. R.; POPKIN, Jeremy. D. (orgs.). Press and Politics in Pre-Revolutionary France. Berkeley: University of California Press, 1987. https://doi.org/10.1525/9780520336452-007

BAKER, Keith M. Defining the Public Sphere in Eighteenth Century France: Variations on a Theme by Habermas. In: CALHOUN, Craig (org.), Habermas and the Public Sphere. Oxford: Mit Press, 1992. p. 181-211.

BARROWS, Susanna. Distorting Mirrors. Visions of the Crowd in Late Nineteenth Century France. New Haven: Yale University, 1981. https://doi.org/10.1086/ ahr/87.4.1106

BIANCO-BRUN, Yves. Le destin d'un fait divers dans l'ancien droit finissant. L'affaire des trois roués. In : AUBIN, G. (org.). Liber amicorum. Études offertes à Pierre Jaubert. Bordeaux : Presses Universitaires de Bordeaux, 1992. p. 77-88.

BIET, Christian. L'opinion publique, le théâtre, le pouvoir, le droit et le brigand. L'affaire Cartouche (1721). In: GAUVARD, Claude (org.). La justice en l'an mil. Paris : Association française pour l'histoire de la justice, 2003. p. 171-185.

CARO BAROJA, Julio. Ensayo sobre la literatura de cordel. Madrid: Istmo, 1990 (1969).

CARRARA, Francesco. I giurati e la libertà. Prolusione al corso accademico di diritto penale dell'anno 1874-75. Lucca: Giusti, 1874.

CAVAGNARI, Camillo. La pubblicità dei dibattimenti e l'educazione del carattere. La Scuola positiva, v. 3, p. 216-224, 1893.

CAVAGNARI, Camillo. Ancora della pubblicità dei dibattimenti e l'educazione del carattere. La Scuola positiva, v. 3, 1893.

DE LUCA, Francesco. L'evoluzione e la giuria. Girgenti: Formica e Gaglio, 1893.

DE ROMANIS, Roberto; LORETELLI, Rosamaria (orgs.). Il delitto narrato al popolo. Immagini di giustizia e stereotipi di criminalità in età moderna. Palermo: Sellerio, 1999. 
DE STÄEL, A.-L. G. Considerazioni sui principali avvenimenti della Rivoluzione francese (1818). Milano: Ispi, 1943.

DEZZA, Ettore. Breve storia del processo penale inglese. Torino: Giappichelli, 2009. FERRI, Enrico. I nuovi orizzonti del diritto e della procedura penale. Prolusione al corso di diritto e procedura penale detta nell'Università di Bologna il 6 dicembre 1880. Bologna: Zanichelli, 1881.

FERRI, Enrico. L'art. 46 c.p. nelle Corti d'Assise. La Scuola Positiva, v. 3, p. 10-19, 1893.

FERRI, Enrico. Sociologia criminale. $3^{\mathrm{a}}$ ed. Torino: Bocca, 1892.

FERRI, Enrico. Sociologia criminale. 5 ed. Torino: Utet, 1929, vol. I.

FERRI, Enrico. I nuovi orizzonti del diritto e della procedura penale. Bologna: Zanichelli, 1884.

FERRI, Enrico. Ricordi e consigli di psicologia oratoria. La Scuola positiva, v. 8, 1898.

FLORIAN, Eugenio. Le due giustizie. Rivista di diritto e procedura penale, p. 143-149, 1910.

FLORIAN, Eugenio. Pel diritto di conoscere i fatti criminosi. La Scuola positiva, V. 3, 1893.

FOUCAULT, Michel. A verdade e as formas jurídicas. Rio de Janeiro: Nau editora, 1996.

FOUCAULT, Michel. Vigiar e Punir: nascimento da prisão. Petrópolis: Vozes, 1987.

FROLA, P. Eugenio. L’ubriachezza alle Corti d'Assise. La Scuola Positiva, v. 3, p. 105-110, 1893.

GAROFALO, Raffaele. Criminologia. Studio sul delitto e sulla teoria della repressione. Torino: Bocca, 1891.

GIANI, R. I giurati e la forza irresistibile. La Scuola Positiva, vol. 1, p. 324-325, 1891.

HABERMAS, Jürgen. Strukturwandel der Öffentlichkeit. Neuwied-Berlin: Luchterhand, 1962.

HABERMAS, Jürgen. Mudança estrutural da esfera pública: investigações quanto a uma categoria da sociedade burguesa. Trad. Flávio R. Kothe. Rio de Janeiro: São Paulo: Brasiliense, 1990.

IMBERT, Jean (org.). Quelques procès criminels des XVII et XVIII siècles. Paris: Puf: 1964.

IMPALLOMENI, Giovanni Battista. Della giuria. Discorso inaugurale letto il 4 novembre 1894 nella R. Università di Palermo. Palermo: Lo Statuto, 1895. 
LACCHÈ, Luigi. Un luogo «costituzionale» dell'identità giudiziaria nazionale: La Corte d'assise e l'opinione pubblica (1859-1913). In: COLAO, Floriana; LACCHÈ, Luigi; STORTI, Claudia (orgs.). Processo penale e opinione pubblica in Italia tra Otto e Novecento. Bologna: Il Mulino, 2008. p. 77-120.

LACCHÈ, Luigi. Una letteratura alla moda. Opinione pubblica, «processi infiniti» e pubblicità in Italia tra Otto e Novecento. In: MILETTI, Marco N. (org.). Riti, tecniche, interessi. Il processo penale tra Otto e Novecento. Milano: Giuffrè, 2006. p. 459-513.

LACCHÈ, Luigi. "L’opinione pubblica saggiamente rappresentata", Giurie e corti d'assise nei processi celebri tra Otto e Novecento. In: MARCHETTI, Paolo (org.). Inchiesta penale e pre-giudizio. Una riflessione inter-disciplinare. Napoli: Esi, 2007, p. 89-147.

LANZA, Pietro. Il processo infinito. Osservazioni in occasione del processo Cifariello. Rivista penale, v. 18, 1908.

LE BON, Gustave. Psychologie des foules. Paris: Félix Alcan, 1895.

LEVER, Maurice. Canards sanglants. Naissance du fait divers. Paris: Fayard, 1993.

LOMBROSO, Cesare. Il governo e la piazza. In: Il momento attuale. Milano: Casa editrice moderna, 1903.

LÜSEBRINK, Hans-Jürgen. Kriminalität und Literatur im Frankreich des 18. Jahrhunderts. Literarische Formen, soziale Funktionen und Wissenskonstituenten von Kriminalitätsdarstellung im Zeitalter der Aufklärung. München-Wien: Oldenbourg Verlag, 1983. https://doi.org/10.1086/ahr/90.2.425

MANGONI, Luisa. Una crisi fine secolo. La cultura italiana e la Francia fra Otto e Novecento, Torino: Einaudi, 1985.

MARTUCCI, Roberto. La Costituente ed il problema penale in Francia (1789-1791). vol. I. Alle origini del processo accusatorio: i decreti Beaumetz. Milano: Giuffrè, 1984.

MARTUCCI, Roberto. Opinion frondeuse, opinion éclairée, opinion publique nella Francia di Antico regime. In: LACCHÈ, Luigi. (org.). Opinione pubblica. Storia, politica, costituzione dal XVII al XX secolo. Número monográfico do Giornale di storia costituzionale, vol. 6, semestre II, 2003.

MAZA, Sarah. Private Lives and Public Affairs. The Causes Célèbres of Prerevolutionary France. Berkeley: University of California Press, 1993.

MAZA, Sarah. Le tribunal de la nation: les mémoires judiciaires et l'opinion publique à la fin de l'ancien régime. Annales Economies, sociétés, civilisations, v. 1, p. 73-90, 1987. https://doi.org/10.3406/ahess.1987.283369 
MAZZACANE, Aldo. Letteratura, processo e opinione pubblica. Le raccolte di cause celebri tra bel mondo, avvocati e rivoluzione. Rechtsgeschichte, v. 3, p. 70-97, 2003. https://doi.org/10.12946/rg03/070-097

MILETTI, Marco N. Un processo per la Terza Italia. Il codice di procedura penale del 1913. vol. I, L'attesa. Milano: Giuffrè, 2003.

MUCCHI FAINA. Angelica. L'abbraccio della folla. Cento anni di psicologia collettiva. Bologna: Il Mulino, 1983.

PALANO, Damiano. Il potere della moltitudine: l'invenzione dell'inconscio collettivo nella teoria politica e nelle scienze sociali italiane tra Otto e Novecento. Milano: Vita \& Pensiero, 2002.

NECKER, Jacques. De l'administration des finances de la France. [S.l.] : [s.n.], 1784.

PESSINA, Enrico. Della instituzione dei giurati nei giudizi penali (1872). In: Opuscoli di diritto penale. Napoli: Marghieri, 1874, vol. I.

PISANI, Mario. Quattro circolari sulla pubblicità del dibattimento. Quaderni fiorentini per la storia del pensiero giuridico moderno, v. 2, p. 703-716, 1973.

POZZOLINI, Alfredo. L'idea sociale nella procedura penale. Appunti critici. Archivio giuridico, v. 60, p. 305-319, 1898; v. 61, p. 30-62, p. 279-303, 1898.

REYNIÉ, Dominique. Gabriel Tarde, théoricien de l'opinion. Paris: Puf, 1989.

SCHNAPPER, Bernard. La diffusion en France des nouvelles conceptions pénales dans la dernière décennie de l'Ancien Régime. In: BERLINGUER, Luigi; COLAO, Floriana (orgs.), Illuminismo e dottrine penali. Milano : Giuffrè, 1990. p. 409-433.

SERGI, Giuseppe. L'educazione del carattere. 2 ed. Milano: Dumolard, 1893.

SIGHELE, Scipio. La Delinquenza settaria. Milano: Treves, 1897.

SIGHELE, Scipio. Lettera di Scipio Sighele a Gabriel Tarde. Critica sociale, $1^{\circ}$ novembre, 1894.

SIGHELE, Scipio. L'intelligenza della folla, Torino: Bocca, 1922.

SIGHELE, Scipio. L'intelligenza della folla. Torino: Bocca, 1931, 2 ed.

SIGHELE, Scipio. La teorica positiva della complicità. Torino: Bocca, 1894.

SIGHELE, Scipio. I delitti della folla studiati secondo la psicologia, il diritto e la giurisprudenza e coll'aggiunta di tutte le sentenze pronunciate dai Tribunali e dalle Corti d'appello in tema di delitto collettivo. Torino: Bocca, 1902.

SIGHELE, Scipio. La folla delinquente. Torino: Bocca, 1891.

SIGHELE, Scipio. Letteratura tragica. Milano: Treves, 1906. 
SIGHELE, Scipio; FERRI, Enrico; LE BON, Gustave et al. Polemica sulla Psychologie des foules. La Scuola Positiva, v. 1, p. 367-375, 1895.

STORTI, Claudi. Giuria penale ed errore giudiziario: questioni e proposte di riforma alle soglie della promulgazione del codice di procedura penale italiano del 1913. In: GOURON, André; MAYALI, Laurent; PADOA-SCHIOPPA, Antonio; SIMON, Dieter (orgs.). Error iudicis. Juristische Wahrheit und justizieller Irrtum. Frankfurt am Main: V. Klostermann, 1998. p. 257-318.

TARDE, Gabriël. Le Public et la Foule. Revue de Paris, n. 15 juillet e $1^{\circ}$ août 1898.

ZACHARIE, Clémence. The Code d'instruction criminelle, 1808. In: The History Website of the Fondation Napoleon, 2008. Disponível em https://www.napoleon. org/en/history-of-the-two-empires/articles/the-code-dinstruction-criminelle-1808/. Acesso em 30 nov. 2020.

\section{Additional information and author's declarations (scientific integrity)}

Conflict of interest declaration: the author confirms that there are no conflicts of interest in conducting this research and writing this article.

Declaration of authorship: all and only researchers who comply the authorship requirements of this article are listed as authors; all coauthors are fully responsible for this work in its entirety.

Declaration of originality: the author assures that the text here published has not been previously published in any other resource and that future republication will only take place with the express indication of the reference of this original publication; he also attests that there is no third party plagiarism considering that this paper is an expanded version of a lecture in the "XIII Encontros de História do Direito: Processo Penal e Modelos de Justiça entre os Séculos XIX e XX” that elaborates on some of the author's ideas already published in other books and papers. 


\section{Editorial process dates}

(http://www.ibraspp.com.br/revista/index.php/RBDPP/about/editorialPolicies)

- Submission: 01/06/2021

- Aprovação final: 07/07/2021

Autor convidado - invited author

\section{Editorial team}

- Editor-in-chief: 1 (VGV)

- Associated-editor: 2 (RS e GM)

\section{COMO CITAR ESTE ARTIGO:}

LACCHÈ, Luigi. Justiça criminal e opinião pública na Itália entre os séculos XIX e XX. Revista Brasileira de Direito Processual Penal, Porto Alegre, vol. 7, n. 2, p. 801-826, mai./ago. 2021.

https://doi.org/10.22197/rbdpp.v7i2.594 